\title{
Bonding performance of a thiohydantoin-methacrylate monomer on noble metal alloys
}

\author{
Kosuke TAKEHANA ${ }^{1}$, Hiroyasu KOIZUMI ${ }^{2,3}$, Haruto HIRABA ${ }^{4,5}$, Akihisa KODAIRA ${ }^{4,5}$, Takayuki YONEYAMA ${ }^{2,3}$ \\ and Hideo MATSUMURA ${ }^{4,5}$
}

\author{
${ }^{1}$ Division of Applied Oral Sciences, Nihon University Graduate School of Dentistry, 1-8-13 Kanda-Surugadai, Chiyoda-ku, Tokyo 101-8310, Japan \\ ${ }^{2}$ Department of Dental Materials, Nihon University School of Dentistry, 1-8-13 Kanda-Surugadai, Chiyoda-ku, Tokyo 101-8310, Japan \\ ${ }^{3}$ Division of Biomaterials Science, Dental Research Center, Nihon University School of Dentistry, 1-8-13 Kanda-Surugadai, Chiyoda-ku, Tokyo 101- \\ 8310, Japan \\ ${ }^{4}$ Department of Fixed Prosthodontics, Nihon University School of Dentistry, 1-8-13 Kanda-Surugadai, Chiyoda-ku, Tokyo 101-8310, Japan \\ ${ }^{5}$ Division of Advanced Dental Treatment, Dental Research Center, Nihon University School of Dentistry, 1-8-13 Kanda-Surugadai, Chiyoda-ku, Tokyo \\ 101-8310, Japan \\ Corresponding author, Hiroyasu KOIZUMI; E-mail: Koizumi.Hiroyasu@nihon-u.ac.jp
}

\begin{abstract}
This study assessed the effect of a primer containing 10-methacryloyloxydecyl-(2-thiohydantoin-4-yl)propionate (MDTHP) on the bonding of noble metal alloys to an acrylic resin. Three noble metal alloys were selected as adherends, and V-Primer containing 6-(4-vinylbenzyl- $n$-propyl)amino-1,3,5-triazine-2,4-dithione was used as a comparative control. The disk specimens of each noble metal alloy were wet-ground and divided into three conditions: specimens primed with MDTHP primer or V-Primer, and specimens without priming. An acrylic resin was bonded to each specimen, and the specimens were performed the shear bond test. The MDTHP primer showed higher shear bond strength than the V-Primer for all specimens. X-ray photoelectron spectroscopic analysis showed that MDTHP was adsorbed on the Au-Pt-Pd alloy surface even after acetone cleaning. MDTHP binds not only with Cu but also with $\mathrm{Au}$ and Ag, promoting the bond strength of noble metal alloys. The effectiveness of MDTHP on dental noble metal alloys was suggested.
\end{abstract}

Keywords: Adhesive, Bonding, Noble metal alloy, Thiohydantoin, Thione

\section{INTRODUCTION}

Noble metal alloys, such as those of gold-copper-silver, gold-platinum-palladium, and silver-palladium-coppergold, are widely used to fabricate restorations and dental prostheses. The long-term prognosis of restorations and dental prostheses depends on the bond strength and durability between the dental alloy and luting agent used. Surface treatment with a primer composed of a sulfur-containing monomer promotes bond strength to noble metal alloys ${ }^{1-6)}$.

Several types of sulfur-containing functional monomers have been developed. The first report on sulfur-containing functional monomers for noble metal alloys was 6-(4-vinylbenzyl- $n$-propyl) amino-1,3,5triazine-2,4-dithiol (VBATDT), which was used as a coating material for copper ${ }^{7}$. VBATDT has been studied for its bonding characteristics with noble metal alloys and is used in clinical practice ${ }^{8-10)}$. The adsorption structure of VBATDT on a noble metal surface has also been analyzed ${ }^{11,12)}$. The analyses showed that VBATDT has a chemically stable thione structure during storage and changes from a thione to thiol structure on the noble metal alloy surface to promote bonding. Analyses using sulfur-containing functional monomers were performed. Imai et al. analyzed the noble metal alloy surface using electron spectroscopy for chemical analysis and

Color figures can be viewed in the online issue, which is available at J-STAGE.

Received Jun 24, 2021: Accepted Oct 27, 2021

doi:10.4012/dmj.2021-181 JOI JST.JSTAGE/dmj/2021-181 confirmed that sulfur-containing functional monomers were adsorbed on the noble metal alloy surface even after rinsing with acetone ${ }^{6}$.

In 2020, the synthesis of a novel sulfur-containing monomer, 10-methacryloyloxydecyl-(2-thiohydantoin4 -yl) propionate (MDTHP), was reported ${ }^{13)}$. MDTHP is a monomer containing thiohydantoin, a five membered heterocyclic compound with a thione structure. The primer containing MDTHP reportedly promotes bond strength between noble metal elements and methyl methacrylate resin ${ }^{14)}$. However, the effect of MDTHP on the bonding of noble metal alloys used in clinical practice has not yet been clarified. This study evaluated the effect of a primer containing MDTHP on the bond strength between noble metal alloys and a methyl methacrylate resin.

\section{MATERIALS AND METHODS}

Three casting alloys - a type IV gold alloy (Au-Cu-Ag; Casting Gold M.C. Type IV, GC, Tokyo, Japan), a gold alloy for metal-ceramic restoration (Au-Pt-Pd; DeguDent U, Degudent, Hanau, Germany), and a silver-palladiumcopper-gold alloy (Ag-Pd-Cu-Au; Castwell M.C. 12\% Gold, GC) were used as the adherend materials.

Two metal priming agents, V-Primer (VP; Sun Medical, Moriyama, Japan) and an MDTHP primer (MP), were assessed as bonding promoters. The VP contained VBATDT monomer. MP was synthesized according to a 
Table 1 Materials assessed in this study

\begin{tabular}{|c|c|c|c|c|}
\hline Material/trade name & Abbr. & Manufacturer & Lot number & Composition \\
\hline \multicolumn{5}{|l|}{ Adherend alloy } \\
\hline Casting Gold M.C. Type IV & $\mathrm{Au}-\mathrm{Cu}-\mathrm{Ag}$ & GC & 702151 & $\begin{array}{l}\text { Au } 70, \mathrm{Cu} 16, \mathrm{Ag} 8, \mathrm{Pd} 3, \mathrm{Pt} 2 \text {, } \\
\text { others } 1 \text { (mass } \%)\end{array}$ \\
\hline DeguDent U & Au-Pt-Pd & Degudent & B013339 & $\begin{array}{l}\text { Au } 77.3, \text { Pt } 9.8, \operatorname{Pd} 8.9, \text { In } 1.5 \text {, } \\
\text { Ag } 1.2 \text {, others } 1.3 \text { (mass } \%)\end{array}$ \\
\hline Castwell M.C.12\% Gold & $\mathrm{Ag}-\mathrm{Pd}-\mathrm{Cu}-\mathrm{Au}$ & GC & $\begin{array}{l}0912101 \\
0812161\end{array}$ & $\begin{array}{l}\mathrm{Ag} 46, \mathrm{Pd} 20, \mathrm{Cu} 20, \mathrm{Au} 12 \text {, } \\
\text { others } 2(\operatorname{mass} \%)\end{array}$ \\
\hline \multicolumn{5}{|l|}{ Primer } \\
\hline V-Primer & VP & \multirow{2}{*}{ Sun Medical } & \multirow{2}{*}{ RE1 } & VBATDT, acetone \\
\hline MDTHP Primer & MP & & & $0.1 \mathrm{~mol} \% \mathrm{MDTHP}$, acetone \\
\hline \multicolumn{5}{|l|}{ Luting material } \\
\hline Methyl methacrylate & & $\begin{array}{l}\text { Tokyo Chemical } \\
\text { Industry }\end{array}$ & YMVAAOL & MMA $99.8 \%$ \\
\hline $\begin{array}{l}\text { Super-Bond C\&B Opaque } \\
\text { Ivory Powder }\end{array}$ & MMA & Sun Medical & $\mathrm{SS} 1, \mathrm{SG} 1$ & PMMA, $\mathrm{TiO}_{2}$ \\
\hline Super-Bond C\&B Catalyst V & & Sun Medical & SS51 & TBB, TBB-O, hydrocarbon \\
\hline
\end{tabular}

VBATDT, 6-(4-vinylbenzyl- $n$-propyl)amino-1,3,5-triazine-2,4-dithione; MDTHP, 10-methacryloyloxydecyl-(2-thiohydantoin4-yl)propionate; MMA, methyl methacrylate; PMMA, polymethyl methacrylate; TBB, tri- $n$-butylborane; TBB-O, partially oxidized tri- $n$-butylborane.

previously described method ${ }^{13)}$. Both primers were of a single liquid type and contained one adhesive monomer in the acetone.

As a luting material, an acrylic resin consisting methyl methacrylate, polymethyl methacrylate, and tri$n$-butylborane was used. The materials used have been summarized in Table 1.

\section{Shear bond strength}

A total of 33 disk specimens were prepared for each Au$\mathrm{Pt}-\mathrm{Pd}$ and $\mathrm{Ag}-\mathrm{Pd}-\mathrm{Cu}-\mathrm{Au}$ alloy, and 22 specimens were prepared for the Au-Cu-Ag alloy. The specimens $(10 \mathrm{~mm}$ in diameter and $3 \mathrm{~mm}$ in thickness) of each alloy were prepared using dental casting technique according to the manufacturer's instructions. All specimens were wet ground with 1500-grit abrasive paper (Wetordry TriM-ite Sheet, 3M, St. Paul, MN, USA) and cleaned with acetone (Tokyo Chemical Industry, Tokyo, Japan) using an ultrasonic bath (SUC-110, Shofu, Kyoto, Japan).

The alloy specimens were evenly assigned $(n=11)$ to one of the following three treatment conditions: 1) unprimed control (UP), 2) primed with VP, and 3) primed with MP. The shear bond strength of UP for the Au-Cu-Ag alloy was quoted by Hiraba et al. ${ }^{12)}$. Each of two primers was applied to the specimen surfaces and air-dried. The bonding area were determined using a masking tape with circular hole $5 \mathrm{~mm}$ in diameter. The luting material was filled into the rings (thickness of 1 $\mathrm{mm}$, height of $2 \mathrm{~mm}$, and inner diameter of $6 \mathrm{~mm}$ ) fixed to the specimens. After half an hour, the specimens were stored at $37^{\circ} \mathrm{C}$ in distilled water for $24 \mathrm{~h}$. Each specimen was seated in a testing jig (ISO TR 11405). Shear bond strengths were determined by means of a universal testing machine (Type 5567, Instron, Canton, MA, USA) at $0.5 \mathrm{~mm} / \mathrm{min}$ crosshead speed.

\section{Failure mode analysis}

After the shear bond test, the debonded alloy surfaces were observed using a stereo microscope (Stemi DV4, Carl Zeiss, Jena, Germany). Image analysis was performed by means of image analysis application (LM eye, Lasertec, Yokohama, Japan), and the cohesive failure ratio was calculated using the following formula: cohesive failure ratio $(\%)=$ cohesive failure area $\left(\mathrm{mm}^{2}\right) \times 100 /$ bonded area $\left(\mathrm{mm}^{2}\right)$.

\section{Scanning electron microscope (SEM) observation}

The debonded alloy surfaces were sputtered with gold and observed using an FE-SEM (ERA-8800FE, Elionix, Tokyo, Japan) with an accelerating voltage of $10 \mathrm{kV}$.

\section{$X$-ray photoelectron spectroscopic analysis}

The primed and unprimed surfaces of the Au-Pt-Pd alloy specimens were analyzed by X-ray photoelectron spectroscopy (XPS; JPS-9010MC, JEOL, Tokyo, Japan). A magnesium anode was used for the measurements with a tube power of $100 \mathrm{~W}$. All spectra were excited using a $\mathrm{Mg} \mathrm{K} \alpha$ line $(1,253.6 \mathrm{eV})$. The vacuum in the chamber during the measurements was in the range of 2.5$4.5 \times 10^{-7} \mathrm{~Pa}$. The detection angle of the photoelectrons 
was $90^{\circ}$ from the surface of the alloy.

The three disk specimens of the Au-Pt-Pd alloy were wet-ground with a 2000-grit abrasive paper and were polished with felt (TexMet 1500, Buehler, Lake Bluff, IL, USA) and diamond suspension $(9,6,3$, and $1 \mu \mathrm{m}$, MetaDi, Buehler). They were cleaned with acetone in the ultrasonic bath. The specimen surfaces were treated under the following three conditions: 1) unprimed, 2) primed with MP, and 3) primed with VP. After priming, all specimens were cleaned with acetone in the ultrasonic bath at $24-31 \mathrm{kHz}$ for $30 \mathrm{~s}$.

Wide scan spectra $(0-1,100 \mathrm{eV})$ were detected by analyzing the specimen surfaces at a pass energy of $50 \mathrm{eV}$. Narrow scan spectra were performed to confirm the presence of certain elements at a pass energy of 20 $\mathrm{eV}$. Qualitative analysis of the spectra was performed using the software (Casa XPS ver. 2.3.13 Dev 34, Casa Software, Teignmouth, UK).

\section{Statistical analysis}

The results of the shear bond test were analyzed using statistical application (GraphPad Prism 9.1.2 software, GraphPad Software, La Jolla, CA, USA). At first, the results were analyzed using the D'Agostino and Pearson omnibus test. When the results of the test did not show a normal distribution, the Kruskal-Wallis test and Dunn's multiple comparison test were performed as nonparametric tests; when the results showed a normal distribution, Dunnett's T3 multiple comparison test was performed. An $\alpha=0.05$ level of the significance was selected for all tests.

\section{RESULTS}

\section{Shear bond strength}

The results of the normality tests for Ag-Pd-Cu-Au (MP group) did not show a normal distribution. Ag-Pd-Cu$\mathrm{Au}$ was therefore analyzed using the nonparametric tests. The Au-Cu-Ag and Au-Pt-Pd showed a normal distribution and were analyzed using Dunnett's T3 multiple comparisons test.

Table 2 presents the results of shear bond strength.

Table 2 Shear bond strength between gold alloy and MMA-TBB resin in MPa

\begin{tabular}{|c|c|c|c|c|c|}
\hline Alloy & Primer & Mean (SD) & Median & IQR & Category \\
\hline \multirow{3}{*}{$\mathrm{Au}-\mathrm{Cu}-\mathrm{Ag}$} & $\mathrm{UP}^{*}$ & $1.6(0.5)$ & 1.8 & 1.0 & $\mathrm{a}$ \\
\hline & $\mathrm{VP}$ & $29.7(1.5)$ & 29.7 & 2.0 & $\mathrm{~b}$ \\
\hline & MP & $32.3(1.1)$ & 32.6 & 1.7 & $\mathrm{c}$ \\
\hline \multirow{3}{*}{$\mathrm{Au}-\mathrm{Pt}-\mathrm{Pd}$} & UP & $1.9(0.5)$ & 2.0 & 0.8 & $\mathrm{a}$ \\
\hline & VP & $20.7(3.7)$ & 21.0 & 6.8 & $\mathrm{~b}$ \\
\hline & MP & $26.2(3.3)$ & 27.0 & 5.0 & $\mathrm{c}$ \\
\hline \multirow{3}{*}{$\mathrm{Ag}-\mathrm{Pd}-\mathrm{Cu}-\mathrm{Au}$} & UP & $1.7(0.9)$ & 2.1 & 1.6 & $\mathrm{a}$ \\
\hline & VP & $29.2(1.5)$ & 29.9 & 2.1 & $\mathrm{~b}$ \\
\hline & $\mathrm{MP}$ & $32.7(0.7)$ & 32.5 & 0.4 & $\mathrm{c}$ \\
\hline
\end{tabular}

$n=11$; SD, standard deviation; IQR, interquartile range; Different categories indicate that the values are significantly different in the statistical analysis performed for each alloy. Data of each of the Au-Cu-Ag and Au-Pt-Pd alloys was analyzed by Dunnett's T3 multiple comparisons, and Ag-Pd-Cu-Au was analyzed by Dunn's multiple comparisons. *The value of UP for the Au-Cu-Ag alloy was quoted from Hiraba et al., 201712).

Table 3 Cohesive failure ratio analysis

\begin{tabular}{|c|c|c|c|c|}
\hline Alloy & Primer & Mean (SD) & Median (\%) & IQR \\
\hline \multirow{3}{*}{$\mathrm{Au}-\mathrm{Cu}-\mathrm{Ag}$} & $\mathrm{UP}^{*}$ & $38 \%(4.8)$ & 36 & 8 \\
\hline & VP & $73 \%(9.8)$ & 73 & 9 \\
\hline & MP & $86 \%(6.7)$ & 86 & 6 \\
\hline \multirow{3}{*}{ Au-Pt-Pd } & UP & $26 \%(2.6)$ & 26 & 4 \\
\hline & $\mathrm{VP}$ & $65 \%(18.4)$ & 68 & 31 \\
\hline & MP & $94 \%(5.0)$ & 97 & 8 \\
\hline \multirow{3}{*}{$\mathrm{Ag}-\mathrm{Pd}-\mathrm{Cu}-\mathrm{Au}$} & UP & $29 \%(2.9)$ & 29 & 5 \\
\hline & $\mathrm{VP}$ & $76 \%(18.6)$ & 81 & 22 \\
\hline & MP & $83 \%(12.7)$ & 90 & 23 \\
\hline
\end{tabular}

$n=11$; Cohesive failure ratio was analyzed using optical micrograph and computer application.

cohesive failure ratio $(\%)=$ cohesive failure area $\left(\mathrm{mm}^{2}\right) \times 100 /$ bonded area $\left(\mathrm{mm}^{2}\right)$

*The value of UP for the Au-Cu-Ag alloy was quoted from Hiraba et al., 2017 ${ }^{12}$. 
The shear bond strengths were categorized into three groups for each alloy (categories a-c). In each alloy, the median bond strengths of MP ranged from 27.0 MPa to 32.6 MPa, showing the highest bond strengths (category c). The median bond strengths of UP ranged from 1.8 $\mathrm{MPa}$ to $2.1 \mathrm{MPa}$, showing the lowest bond strengths (category a). MP exhibited a higher bond strength than VP for all alloys. These results suggest that MP is effective in promoting bond strength between noble metal alloys and acrylic resin.

\section{Failure mode analysis}

Table 3 presents the results of the failure mode analysis. The median cohesive failure ratio varied from a minimum of $26 \%$ to a maximum of $97 \%$ and showed higher values for MP in each alloy, as well as the bond strength.

\section{SEM observation}

Figure 1 shows the scanning electron images of the debonded surfaces. Figures 1a, c, and e show the surfaces of each alloy specimen primed with VP, and Figs. 1b, d, and $f$ show the surfaces of each alloy specimen primed with MP. Remnants of the debonded resin were observed on the surfaces of all the primed specimens (Figs. 1a-f).

\section{XPS analysis}
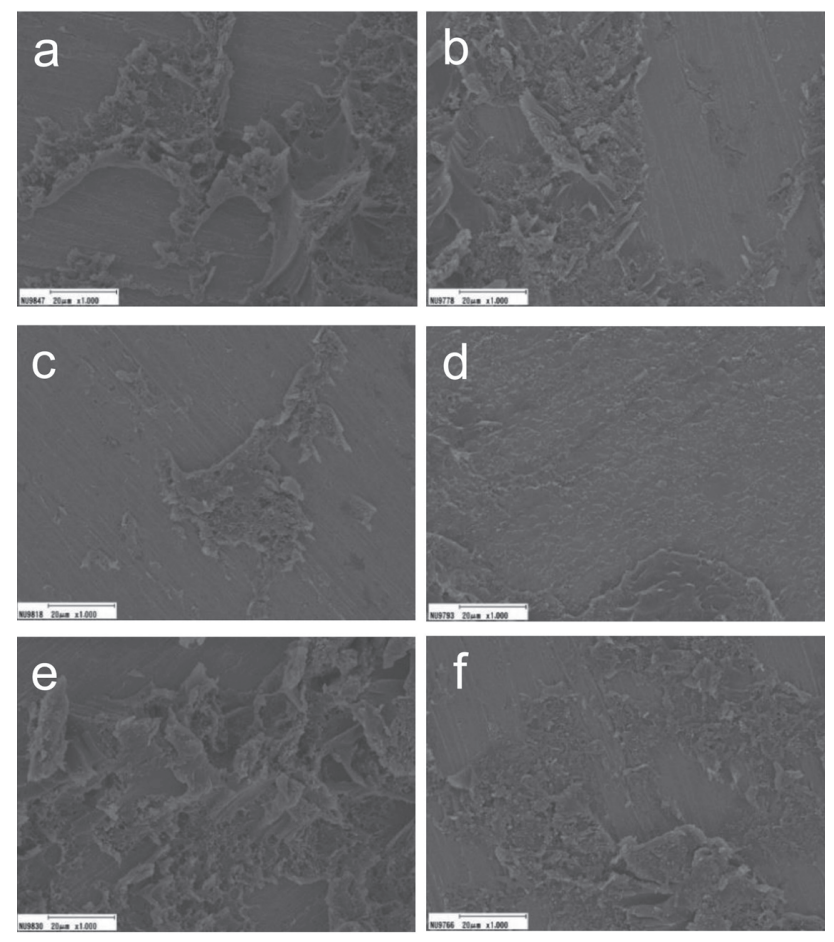

Fig. 1 SEM images of the debonded alloy surfaces, (a) Au$\mathrm{Cu}-\mathrm{Ag}$ alloy primed with $\mathrm{VP}$, (b) $\mathrm{Au}-\mathrm{Cu}-\mathrm{Ag}$ alloy primed with MP, (c) Au-Pt-Pd alloy primed with $\mathrm{VP},(\mathrm{d}) \mathrm{Au}-\mathrm{Pt}-\mathrm{Pd}$ alloy primed with MP, (e) Ag-Pd$\mathrm{Cu}-\mathrm{Au}$ alloy primed with $\mathrm{VP}$, and (f) $\mathrm{Ag}-\mathrm{Pd}-\mathrm{Cu}-$ $\mathrm{Au}$ alloy primed with MP (original magnification $\times 1,000)$.
Figure 2 shows the wide scan spectra of the Au-Pt-Pd surface treated under three conditions: 1) unprimed, 2) primed with MP, and 3) primed with VP. The narrow scan spectra of C $1 s, \mathrm{~N} 1 s, \mathrm{~S} 2 p, \mathrm{Au} 4 f 5 / 2$, Au 4f7/2, Ag $3 d 3 / 2$ and $\mathrm{Ag} 3 d 5 / 2$ on the Au-Pt-Pd surface were also analyzed under the same conditions (Figs. 3-5). The peaks of $\mathrm{N} 1 s$ and $\mathrm{S} 2 p$ were detected on all specimen
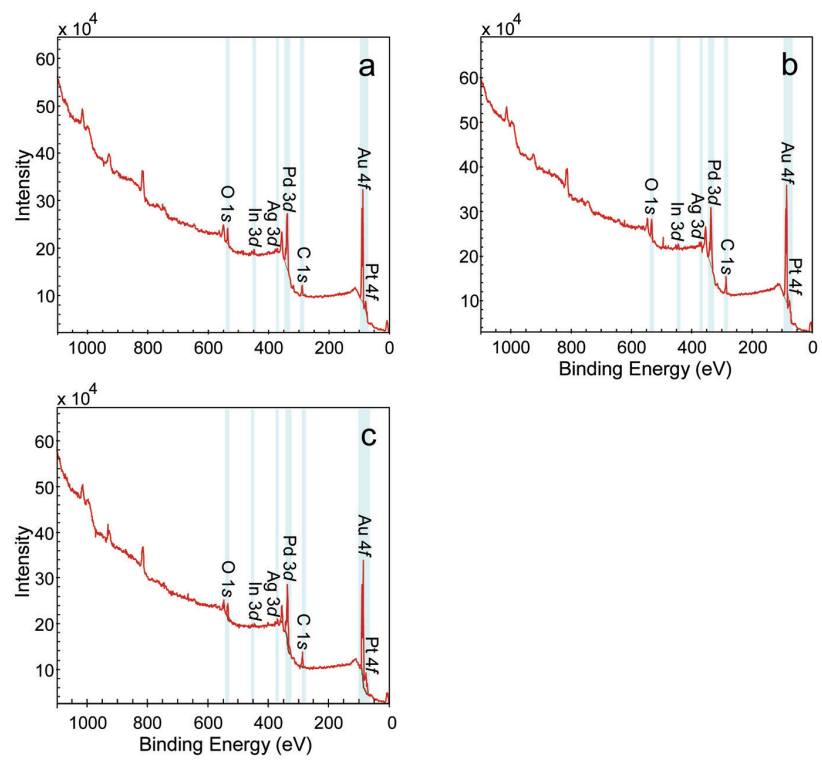

Fig. 2 XPS wide scan spectra of polished Au-Pt-Pd alloy surfaces, (a) unprimed, (b) primed with MP, and (c) primed with VP.
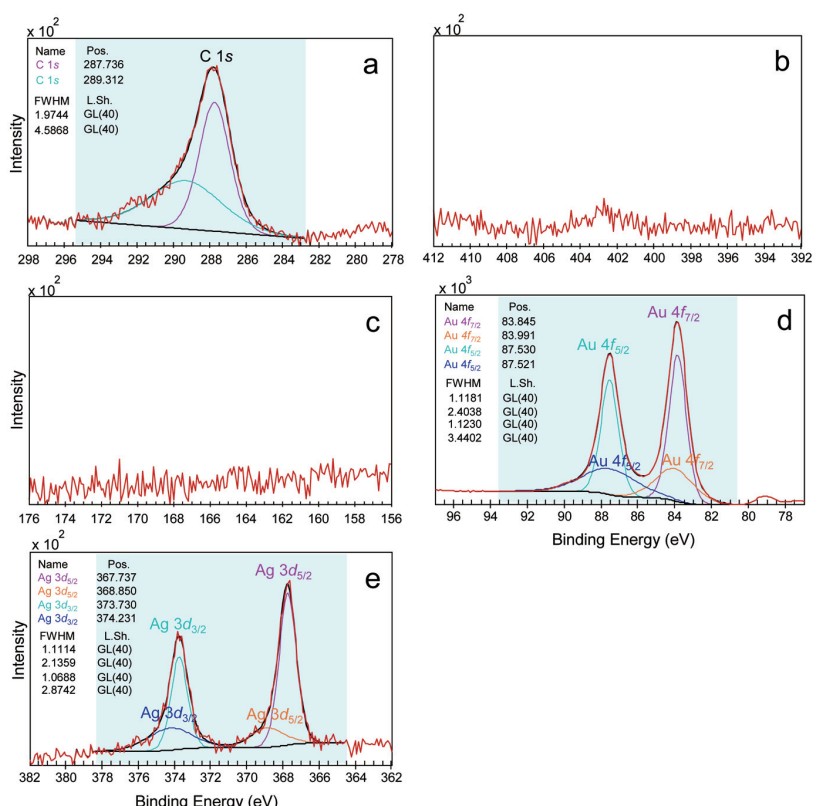

Fig. 3 XPS narrow scan spectra of the $\mathrm{C} 1 s$ (a), N $1 s$ (b), S $2 p$ (c), Au 4f5/2 and $\mathrm{Au} 4 f 7 / 2$ (d), and $\mathrm{Ag} 3 d 3 / 2$ and $\mathrm{Ag} 3 d 5 / 2$ (e) regions of the polished and unprimed Au-Pt-Pd specimen. 


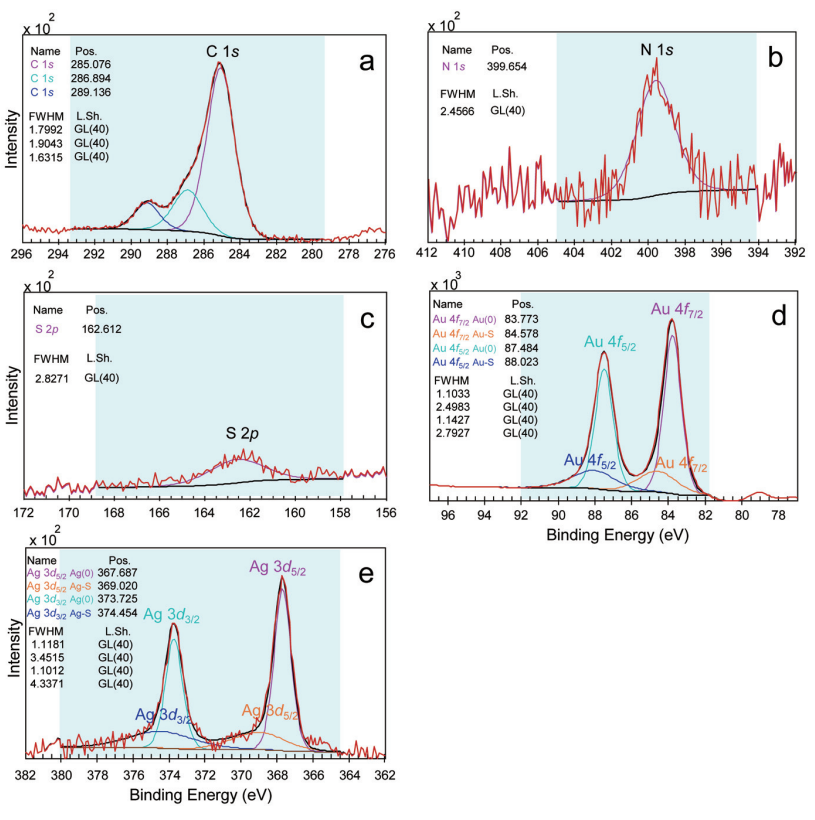

Fig. 4 XPS narrow scan spectra of the $\mathrm{C} 1 s$ (a), N $1 s$ (b), $\mathrm{S} 2 p$ (c), Au 4f5/2 and Au 4f7/2 (d), and Ag 3d3/2 and $\mathrm{Ag} 3 d 5 / 2$ (e) regions of the Au-Pt-Pd specimen primed with MP.
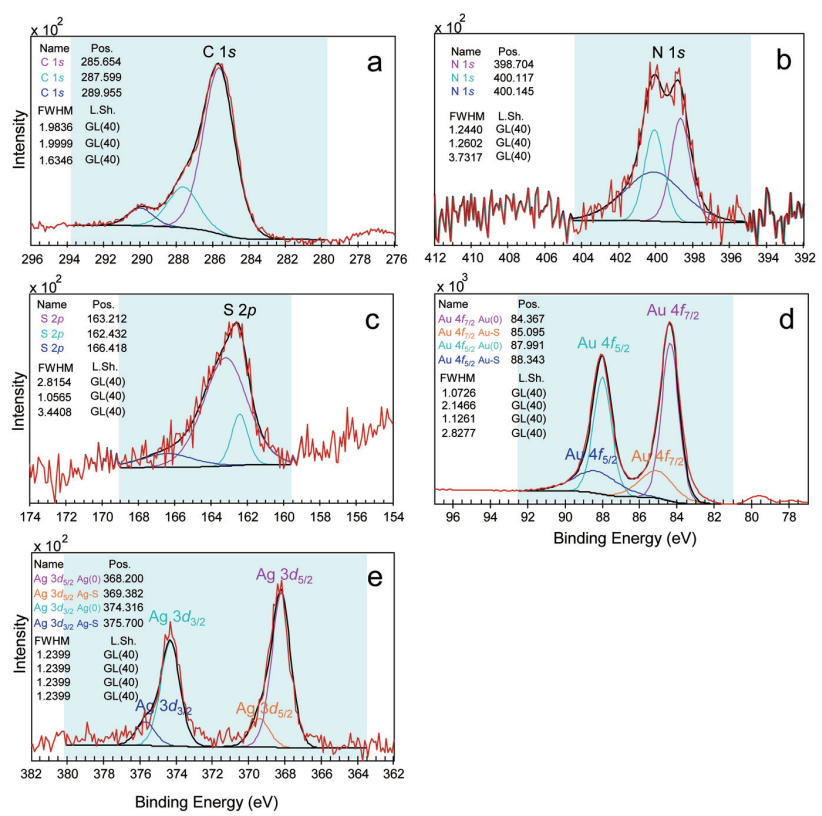

Fig. 5 XPS narrow scan spectra of the $\mathrm{C} 1 s$ (a), N $1 s$ (b), $\mathrm{S} 2 p$ (c), Au 4f5/2 and Au 4f7/2 (d), and Ag 3d3/2 and $\mathrm{Ag} 3 d 5 / 2$ (e) regions of the Au-Pt-Pd specimen primed with VP.

Table 4 Peaks of bonding energies (eV) obtained from the Au-Pt-Pd specimens primed with VP

\begin{tabular}{lccc}
\hline Element & Peak energy $(\mathrm{eV})$ & Peak assignment (Compound) & References values $(\mathrm{eV})$ \\
\hline $\mathrm{C} 1 s$ & 285.654 & $\left(\mathrm{CH}_{2}\right)_{n}$ & $285.10^{18)}$ \\
$\mathrm{Au} 4 f 7 / 2$ & 84.367 & $\mathrm{Au}(0)$ & $83.3^{17)}$ \\
$\mathrm{Au} 4 f 7 / 2$ & 85.095 & $\mathrm{Au}-\mathrm{S}$ & $84.6^{17)}$ \\
$\mathrm{Au} 4 f 5 / 2$ & 87.991 & $\mathrm{Au}(0)$ & $86.9^{17)}$ \\
$\mathrm{Au} 4 f 5 / 2$ & 88.343 & $\mathrm{Au}-\mathrm{S}$ & $88.2^{17)}$ \\
$\mathrm{Ag} 3 d 5 / 2$ & 368.200 & $\mathrm{Ag}(0)$ & $367.9^{20)}$ \\
$\mathrm{Ag} 3 d 5 / 2$ & 369.382 & $\mathrm{Ag}-\mathrm{S}$ & $368.6^{20)}$ \\
$\mathrm{Ag} 3 d 3 / 2$ & 374.316 & $\mathrm{Ag}(0)$ & $373.8^{20)}$ \\
$\mathrm{Ag} 3 d 3 / 2$ & 375.700 & $\mathrm{Ag}-\mathrm{S}$ & $374.7^{20)}$ \\
$\mathrm{S} 2 p$ & 162.432 & $\mathrm{~S}-\mathrm{Au}, \mathrm{S}-\mathrm{Ag}$ & $162.13^{16)}, 161.67^{19)}$ \\
$\mathrm{S} 2 p$ & 163.212 & $\mathrm{~S}-\mathrm{H}$ & $163.35^{16)}$ \\
\hline
\end{tabular}

surfaces except the unprimed specimen. The peaks attributed to the $\mathrm{Au}-\mathrm{S}^{15-17)}$ bond were observed at 84.578 eV (Fig. 4d) and $85.095 \mathrm{eV}$ (Fig. 5d) in the spectra of $\mathrm{Au} 4 f 7 / 2$, and at $88.023 \mathrm{eV}$ (Fig. 4d) and $88.343 \mathrm{eV}$ (Fig. $5 \mathrm{~d})$ in the spectra of $\mathrm{Au} 4 f 5 / 2$. The peaks attributed to the Ag- ${ }^{18-20)}$ bond were observed at $369.020 \mathrm{eV}$ (Fig. 4e) and $369.382 \mathrm{eV}$ (Fig. 5e) in the spectra of $\mathrm{Ag} 3 d 5 / 2$, and at $374.454 \mathrm{eV}$ (Fig. 4e) and $375.700 \mathrm{eV}$ (Fig. 5e) in the spectra of $\mathrm{Ag} 3 d 3 / 2$. The peaks obtained from the AuPt-Pd specimens primed with VP are also presented in
Table 4.

\section{DISCUSSION}

The effect of primers containing MDTHP on the bonding of noble metal alloys was assessed. Kodaira et al. reported on a study using MDTHP and VBATDT for elemental noble metal alloys. MDTHP showed high bond strength with elemental noble metal alloys, especially copper $^{14)}$. However, the effects on noble metal alloys 
have not yet been clarified. Therefore, three dental noble metal alloys with different compositions were selected as adherends, and the shear bond strengths of each alloy were compared.

The organic sulfur compound showed higher shear bond strength to noble metal alloys than UP, as previously reported. In addition, the shear bond strength of MP was significantly higher than that of VP in each alloy. MP showed high shear bond strength to the Au$\mathrm{Cu}-\mathrm{Ag}$ and $\mathrm{Ag}-\mathrm{Pd}-\mathrm{Cu}-\mathrm{Au}$ alloys, which are noble metal alloys containing copper. MP was also effective for the Au-Pt-Pd alloy, which scarcely contained copper. The cohesive failure ratio was calculated by image analysis of the specimen debonded surface after the shear bond strength tests, and the MP showed a high value for each alloy. The cohesive failure ratio and the shear bond strength values showed similar trends. As a result of the SEM observation of the debonded surface, resin remnants were observed on all surface-treated specimen surfaces (Fig. 1). The observed SEM images were similar to those previously reported for organic sulfur compounds ${ }^{21}$.

Surface analysis by XPS was performed to confirm the adsorption state of MDTHP on the surfaces of the Au-Pt-Pd alloy. MDTHP has a thiohydantoin structure, which is a five membered heterocyclic compound with a thione group, and can be tautomerized in the same way as VBATDT ${ }^{14}$. The peaks of sulfur and nitrogen, which are elements derived from MDTHP, were detected on the surface of the Au-Pt-Pd alloy even after acetone cleaning for $30 \mathrm{~s}$ using an ultrasonic bath after the MP treatment (Figs. $4 \mathrm{~b}$ and c). This suggests that MDTHP is strongly adsorbed on Au-Pt-Pd alloy surfaces. Kodaira et $a l$. analyzed the copper surface by XPS using MDTHP ${ }^{14)}$. The peaks of sulfur and nitrogen were detected on the copper surface, indicating that MDTHP adsorbed on the copper surface promoted bonding ${ }^{14}$. However, MP showed a high bond strength to the Au-Pt-Pd alloy, which scarcely contained copper. XPS analysis was performed on the Au-Pt-Pd alloy to clarify which elements other than copper are bound to MDTHP. Suzuki et al. reported the chemisorption of VBATDT on Au and Ag substrates using Raman scattering techniques ${ }^{22)}$. XPS analysis of the bonding of $\mathrm{Au}$ and $\mathrm{Ag}$ in noble metal alloys with organic sulfur compounds has not been performed. Therefore, XPS analysis was performed using VBATDT. Because alloys scarcely containing copper were used, the specimens could be observed without considering the effect of copper. With XPS analysis, a peak attributable to the intermediate chain ${ }^{18)}$ of VBATDT was observed in the narrow scan spectrum of $\mathrm{C} 1 s$, and peaks attributable to $\mathrm{Au}-\mathrm{S}^{15-17)}$ and $\mathrm{Ag}-\mathrm{S}^{18-20)}$ bonds were detected in the narrow scan spectra of Au 4f7/2, Au 4f5/2, Ag 3d5/2, Ag 3d3/2, and S $2 p$ (Table 4 and Fig. 5). The narrow scan spectra of $\mathrm{Au} 4 f 7 / 2, \mathrm{Au} 4 f 5 / 2, \mathrm{Ag} 3 d 5 / 2$, and $\mathrm{Ag} 3 d 3 / 2$ showed chemical shifts coincident with previous reports ${ }^{17,20)}$ (Table 4 and Fig. 5). Similar peaks and chemical shifts to those of VBATDT were observed for MDTHP (Figs. 4, 5 and Table 4). MDTHP is assumed to promote the bond strength in copper-free noble metal alloys by adsorbing on $\mathrm{Au}$ or $\mathrm{Ag}$ instead of $\mathrm{Cu}$.
Bonding performance of organic sulfur compounds to noble metal elements has been reported previously ${ }^{14,23)}$. Kodaira et al. reported that MDTHP showed high bond strength to $\mathrm{Cu}, \mathrm{Au}$, and $\mathrm{Ag}^{14)}$. It showed high bond strength with $\mathrm{Au}-\mathrm{Cu}-\mathrm{Ag}$ and $\mathrm{Ag}-\mathrm{Pd}-\mathrm{Cu}-\mathrm{Au}$ alloys and inferior bond strength with the Au-Pt-Pd alloy. From the results, it was speculated that in comparison with $\mathrm{Au}-\mathrm{S}$ and $\mathrm{Ag}-\mathrm{S}$ bonds, the $\mathrm{Cu}-\mathrm{S}$ bond may be more related to the bond strength of the noble alloys.

Another organic sulfur compound is 6-methacryloyloxyhexyl 2-thiouracil-5-carboxylate (MTU-6). The primer containing MTU-6 is Metaltite (Tokuyama Dental, Tokyo, Japan). Hiraba et al. reported the Metaltite primer copolymerized with the TBB-initiated methacrylic resin and improved bonding to the $\mathrm{Au}-\mathrm{Cu}-\mathrm{Ag}$ alloy ${ }^{12,21}$. The Metaltite primer was not assessed as a comparison in this study. The Metaltite primer contains ethanol as a solvent, therefore, VP and MP, which contain acetone as a solvent, were used for comparison in this study. In future, other organic sulfur compounds used in clinical practice will also be included for comparison.

In conclusion, the primer containing MDTHP showed superior bond strength between noble metal alloys and an acrylic resin compared to the primer containing VBATDT. The effect of MDTHP on the bond durability of noble metal alloys will be the subject of further study. The adsorption of MDTHP on the noble metal alloy surface was confirmed even after cleaning with acetone. MDTHP binds not only with $\mathrm{Cu}$ but also with $\mathrm{Au}$ and $\mathrm{Ag}$, promoting the bond strength of noble metal alloys. These results suggest that MDTHP is effective for use with dental noble metal alloys.

\section{ACKNOWLEDGMENTS}

This study was supported in part by a grant (2021) from the Dental Research Center, Nihon University School of Dentistry. The authors thank Dr. Peng Chen of Tokyo Medical and Dental University for assistance with the $\mathrm{X}$-ray photoelectron spectroscopic analysis.

\section{CONFLICT OF INTEREST}

The authors declare that they have no conflicts of interest.

\section{REFERENCES}

1) Matsumura H, Kamada K, Tanoue N, Atsuta M. Effect of thione primers on bonding of noble metal alloys with an adhesive resin. J Dent 2000; 28: 287-293.

2) Ishii $T$, Koizumi H, Yoneyama $T$, Tanoue $N$, Ishikawa $\mathrm{Y}$, Matsumura H. Comparative evaluation of thione and phosphate monomers on bonding gold alloy and Ti-6Al-7Nb alloy with tri- $n$-butylborane initiated resin. Dent Mater J 2008; 27: 56-60.

3) Yamashita M, Koizumi H, Ishii T, Furuchi M, Matsumura H. Evaluation of thiouracil-based adhesive systems for bonding cast silver-palladium-copper-gold alloy. J Oral Sci 2010; 52: 405-410.

4) Shimoe S, Tanoue N, Satoda T, Murayama T, Nikawa H, 
Matsumura H. Evaluation of single liquid primers with organic sulfur compound for bonding between indirect composite material and silver-palladium-copper-gold alloy. Dent Mater J 2010; 29: 25-29.

5) Minami H, Murahara S, Suzuki S, Tanaka T. Effects of metal primers on the bonding of an adhesive resin cement to noble metal ceramic alloys after thermal cycling. J Prosthet Dent 2011; 106: 378-385.

6) Imai H, Koizumi H, Shimoe S, Hirata I, Matsumura H, Nikawa H. Effect of thione primers on adhesive bonding between an indirect composite material and Ag-Pd-Cu-Au alloy. Dent Mater J 2014; 33: 681-688.

7) Mori K, Nakamura Y. Study on triazine thiols. V. Polymerization of 6-(4-vinylbenzyl propyl)amino-1,3,5triazine-2,4-dithiol on copper plates and their corrosion resistance. J Polym Sci Polym Lett Ed 1983; 21: 889-895.

8) Atsuta M, Matsumura H, Tanaka T. Bonding fixed prosthodontic composite resin and precious metal alloys with the use of a vinyl-thiol primer and an adhesive opaque resin. J Prosthet Dent 1992; 67: 296-300.

9) Matsumura H, Shimoe S, Nagano K, Atsuta M. Effect of noble metal conditioners on bonding between prosthetic composite material and silver-palladium-copper-gold alloy. J Prosthet Dent 1999; 81: 710-714.

10) Koizumi H, Ishii T, Naito K, Yoneyama T, Tanoue N, Matsumura H. Effects of triazine dithione and hydrophobic phosphate monomers on bonding to Ag-Pd-Cu-Au alloy and titanium with a methacrylic resin-based luting agent. J Adhes Dent 2010; 12: 215-222.

11) Suzuki M, Fujishima A, Miyazaki T, Hisamitsu H, Kojima K, Kadoma Y. A study on the adsorption structure of an adhesive monomer for precious metals by surface-enhanced Raman scattering spectroscopy. Biomaterials 1999; 20: 839845 .

12) Hiraba H, Koizumi H, Nogawa H, Kodaira A, Okamura K, Matsumura H. Trace of organic sulfur compounds detected from debonded interface between transparent acrylic resin and gold alloy. J Oral Sci 2017; 59: 511-517.

13) Matsumura H, Kojima K, Mio S, Yamamoto T, Kodaira A, Koizumi H. Synthesis and characterization of a methacrylate monomer with thiohydantoin structure. J Oral Sci 2020; 62: 256-258.

14) Kodaira A, Koizumi H, Hiraba H, Takehana K, Yoneyama
T, Matsumura H. Adhesive bonding of noble metals with a thiohydantoin primer. Dent Mater 2021; 37: 176-181.

15) Laiho T, Leiro JA, Lukkari J. XPS study of irradiation damage and different metal-sulfur bonds in dodecanethiol monolayers on gold and platinum surfaces. Appl Surf Sci 2003; 525: 212-213.

16) Battocchio C, Porcaro F, Mukherjee S, Magnano E, Nappini $\mathrm{S}$, Fratoddi I, et al. Gold nanoparticles stabilized with aromatic thiols: Interaction at the molecule-metal interface and Lligand arrangement in the molecular shell investigated by SR-XPS and NEXAFS. J Phys Chem C 2014; 118: 81598168.

17) Gade M, Khandelwal P, Sangabathuni S, Bavireddi H, Murthy RV, Poddar P, et al. Immobilization of multivalent glycoprobes on gold surfaces for sensing proteins and macrophages. Analyst 2016; 141: 2250-2258.

18) Laiho T, Leiro JA, Heinonen MH, Mattila SS, Lukkari J. Photoelectron spectroscopy study of irradiation damage and metal-sulfur bonds of thiol on silver and copper surfaces. J Electron Spectrosc Relat Phenom 2005; 142: 105-112.

19) Battocchio C, Meneghini C, Fratoddi I, Venditti I, Russo MV, Aquilanti G, et al. Silver nanoparticles stabilized with thiols: A close look at the local chemistry and chemical structure. J Phys Chem C 2012; 116: 19571-19578.

20) Cova CM, Zuliani A, Santiago ARP, Caballero A, MuñozBatista MJ, Luque R. Microwave-assisted preparation of Ag/ $\mathrm{Ag}_{2} \mathrm{~S}$ carbon hybrid structures from pig bristles as efficient HER catalysts. J Mater Chem A Mater 2018; 6: 2151621523.

21) Hiraba H, Nogawa H, Koizumi H, Kodaira A, Akahane S. Effect of multi-purpose primers on the bond durability between tri- $n$-butylborane initiated resin and gold alloy. $\mathrm{J}$ Prosthodont Res 2019; 63: 95-99.

22) Suzuki M, Yamamoto M, Fujishima A, Miyazaki T, Hisamitsu $\mathrm{H}$, Kojima K, et al. Raman and IR studies on adsorption behavior of adhesive monomers in a metal primer for $\mathrm{Au}, \mathrm{Ag}$, $\mathrm{Cu}$, and $\mathrm{Cr}$ surfaces. J Biomed Mater Res 2002; 62: 37-45.

23) Yamashita M, Koizumi H, Ishii T, Nakayama D, Oba Y, Matsumura H. Adhesive performance of silver-palladiumcopper-gold alloy and component metals bonded with organic sulfur-based priming agents and a tri- $n$-butylborane initiated luting material. Acta Odontol Scand 2013; 71: 196-204. 